\title{
BEYOND ICONICITY: OSTENSION IN KAMSÁ MYTHIC NARRATIVE
}

\author{
John H. McDowell
}

The chain of verbs-Veni, vidi, vici-informs us about the order of Ceasar's deeds first and foremost because the sequence of co-ordinate preterits is used to reproduce the succession of reported occurrences.

-Roman Jakobson

The notion has been much abroad lately, among folklorists and others dealing with narrative materials, that the essence of a narrative is preserved in the printed synopsis of its content. ${ }^{1}$ Claude LéviStrauss, to cite only one prominent example, takes the synopsis of mythological texts as the ultimate empirical grounding, the raw material from which all analysis and interpretation proceeds. To be sure, these synopses are supplemented with ethnographic accounts when convenient, so that the mythologies are not treated in entirely disembodied form. But one part of the ethnographic background is conspicuously absent in Lévi-Strauss' writing, namely, details of the performance settings fostering the creation of mythological discourse. This neglect is the result of a scholarly design aimed at revealing "how myths operate in men's minds without their being aware of the fact." 2 In such an enterprise, one can readily disregard the rhetorical dimensions of mythological discourse, the musicality of its language, and its affective, artistic qualities, for these are matters that relocate the thrust of inquiry to the plane of situated human intercourse.

There can be little doubt that this orientation towards the content of narrative has produced interesting results; at the same time, it 
has ignored other equally important aspects of narrative. Lévi-Strauss' assertion that the substance of myth "does not lie in its style, its original music, or its syntax, but in the story which it tells"3 can be challenged as an unwarranted transformation of a methodological principle into an article of belief concerning the nature of reality. Convincing counter-arguments have been developed by Dennis Tedlock and others who have come into close contact with the music of mythological discourse. ${ }^{4}$ Beyond the issue of the musicality of mythological discourse, we must still confront a series of problems deriving from the assumption that the story told inheres in the synopsis of plot content. Folklorists are becoming increasingly sensitive to the rhetorical dimensions of narrative discourse associated with its performance within the native situational context. ${ }^{5}$ Most performances dramatize their plots to a greater or lesser degree, and it is precisely these dramatic devices that are perishable in the distillation of the printed synopsis. The rhetoric cannot be retained in the synopsis, which tends to assimilate nuances of phrasing, timing, and framing into an abbreviated presentational format.

Synopsis, after all, is but a fourth-generation image of its original, and as with photographic or magnetic-tape copying, some fidelity to the original is lost with each generation. The original is the performance in all of its vibrant, multidimensional complexity. The second generation is the transcript, which already severely compromises the original by reducing it to the proportions allowed by the conventions of alphabetic systems. These systems are geared to the retrieval of brute linguistic facts and are ill-suited to the conservation of paralinguistic features. Steps can be taken to include these features, but always at the risk of burdening the transcription with excessive detail and thereby destroying its accessibility.

The third generation is the translation. Without a companion text in the original language, we cannot recover the musicality of narrative, necessarily determined by the phonological features of the host language. Translation may aim at the recreation of comparable phonological effects but often at the cost of sacrificing semantic fidelity. At best, translation is a workable compromise, without valid claim to a faithful rendering of its original text. ${ }^{6}$

The fourth generation appears when the translation is reduced to a synopsis. The synopsis eliminates seemingly repetitive or inconsequential material not critical to the bald presentation of the plot. It discards precisely that material which is responsible for the creation of dramatic, affective narrative performances. With its mission of 
brevity, the synopsis is prone to substitute schematic paraphrase for involuted narrative segments or to replace instances of reported speech with third person summaries. These alterations severely deprive the performances of their capacity to inspire pity and fear, of their capacity to enlist the sentiments of the audience in an affective communicative experience. The following chart summarizes the drift towards infidelity to the original performance, reaching its culmination in the printed synopsis:

\begin{tabular}{|c|c|c|}
\hline $1^{\text {st }}$ generation & PERFORMANCE & \\
\hline $2^{\text {nd }}$ generation & TRANSCRIPTION & $\begin{array}{l}\text { (loss of paralinguistic } \\
\text { features, gestures) }\end{array}$ \\
\hline $3^{\text {rd }}$ generation & Translation & $\begin{array}{l}\text { (loss of stylistic and } \\
\text { semantic fidelity) }\end{array}$ \\
\hline $4^{\text {th }}$ generation & synopsis & $\begin{array}{l}\text { (loss of dramatic and } \\
\text { rhetorical elements) }\end{array}$ \\
\hline
\end{tabular}

In this paper I address this loss of fidelity occasioned in the movement from transcription (translated or otherwise) to the printed synopsis of a performance. I will establish a semiotic framework to account for the vivification of narrative, the breathing of life into a skeletal plot structure. I suggest that narrative is a form of verbal icon that tends towards the transcendence of iconicity by creating the illusion of ostension, a radically different mode of semiosis. Ostension precipitates a form of narrative epiphany, a stirring breakthrough from one level of being to another. The affective qualities of narrative, pivotal to the community supporting the narrative tradition, are generally inaccessible to scholars working solely from synopsized texts. My commentary will be anchored in the mythic narrative tradition of the Kamsá Indians of Andean Colombia, a tradition I was privileged to listen in on during the period 1978-79.

\section{Narrative as Verbal Icon}

Nils Erik Enkvist has recently proposed the term experiential iconicism, a "mimetic isomorphism" wherein "the text becomes an icon of experience." ${ }^{7}$ Experiential iconicism is present when "the linear relations in a text stand for temporal, causal, spatial, or social relations between referents in the world described by that text." ${ }^{8} \mathrm{I}$ had independently pursued a parallel line of reasoning with respect to the discourse of the Mexican corrido, which I viewed as an icon of some presumed experiential substratum. ${ }^{9}$ In the following pages I will develop a more thorough account of iconicity in narrative, with reference to temporal 
sequencing in discourse and in experience, using the concept of temporal juncture as developed by William Labov as a point of departure. Labov defines narrative as "one method of recapitulating experience by matching a verbal sequence of clauses to the sequence of events which (it is inferred) actually occurred." 10 The minimal narrative, in these terms, is "a sequence of two clauses which are temporally ordered.... There is a temporal juncture between the two clauses." 11 Larger narratives would contain a more extensive chain of temporallyordered clauses. There is a good deal more to Labov's analysis, but for the moment let me seize only on this concept of temporal juncture.

The concept of temporal juncture in narrative clauses entails a precise homology between an inferential sequence of events (the experiential substrate) and a verbal recounting of this sequence (the narrative discourse). The components of this homology are the moments of temporal juncture which are presumably embedded in the experiential substrate and replicated in the narrative discourse. In this particular I depart from Labov's analysis, which locates temporal juncture exclusively in the narrative discourse. I suggest that the iconicity resides in the capacity of the discourse to replicate a chain of temporal juncture located in some experiential substrate. Narratives are verbal icons of experience in that they reproduce intact (or allow for the recovery of) an ordered sequence of events presumably encountered beyond the narrative itself.

The experiential substrate is a problematic but necessary concept. It is kindred to what Seymour Chatman denotes as story, that is, "the continuum of events presupposing the total set of all conceivable details." ${ }^{12}$ As such, it is a purely speculative construct; only an omniscient mind could comprehend the entirety of any experiential substrate, and even in the most factual of personal experience narratives, the experiential substrate is perhaps ultimately unverifiable. Yet all narrative forms presuppose this ideal continuum of events, without which the discourse would be unmotivated. Narratives implicitly or explicitly evoke an experiential substrate in order to anchor the discourse in some autonomous chronology.

The realization of any experiential substrate in narrative discourse involves a tremendous phenomenological compromise. The discourse produces only a small fraction of the total inventory of detail attributable to the experiential substrate. Frank Kermode has written that "all narratives are essentially dark, despite the momentary radiance that attends divination." ${ }^{13}$ He draws attention to "the sensory limitations to which narratives are prone: blindness, deafness, an in- 
termittency of memory." 14 Elsewhere I have shown how the traditional corrido of greater Mexico, a ballad form, tends to be inscrutable, relying on ancilliary sources of information for elucidation. ${ }^{15}$ All narratives partake of this inscrutability to some degree since narrative discourse is only a partial and incomplete iconic representation of its experiential substrate.

While the discussion so far has suggested the priority of the experiential substrate, this priority is often logical rather than operational. In the speech act of narration, the narrator assumes responsibility for formulating the experiential substrate through the articulation of narrative discourse. The experiential substrate, logically prior to the discourse, actually takes shape in the words produced by the narrator. The narrator enjoys the formidable power of bringing a world into existence through the production of speech, subject of course to the demands of internal consistency, to conventions of style and content associated with particular genres, and to the audience's familiarity with the traditional themes.

Narrative discourse points to a preordained experiential substrate, but, in actuality, it formulates or reformulates the substrate in the act of narrating. Clearly, some genres impose considerable restrictions on the narrator's license in this regard. Where an orthodox experiential substrate exists, the narrator may be obliged to adhere rather closely to this traditional charter. But a number of traditions provide scope for "the adopting of various strategies for the encompassing of situations," to cite Kenneth Burke's felicitous observation. ${ }^{16}$ In these settings the narrator formulates an idiosyncratic version of some experiential substrate, and as long as the discourse conforms to the strictures of what Kermode calls "followability,"17 it will be taken as a plausible rendition of an actual experiential substrate.

The conceptualization of narrative as verbal icon provides some insight into certain classical problems in literary and folkloristic studies, such as genre differentiation and the definition of point of view. One critical factor in genre definition is the location of the presumed experiential substrate within the mythical, fictional, or historical realms. ${ }^{18}$ Myth invokes a substrate which is assumed to have actually happened in a precultural time frame when many things were possible which are no longer possible. Fiction invents an imaginary substrate which gains plausibility to the extent that it resembles some actual experiential substrates. Historical narrative presents a substrate which is assumed to have actually happened in a world much like our own. 
Narrators exercise several options with respect to their own orientations towards the experiential substrate of the narrative. In personal experience narratives, the substrate is assumed to lie within the biography of the narrator though this is often a demonstrably hollow convention. In legend, on the other hand, the substrate is projected into the biography of someone other than the narrator. Narrators may present themselves as participants in the events, as witnesses to these events, or as neither. These validational tactics constitute a rich rhetorical domain in their own right. ${ }^{18}$

Genres can be further distinguished with respect to the nature of the discourse they employ. When narrative is seen as verbal icon, the transparency or opacity of the discourse clearly emerges. In one discourse mode, especially associated with oral narrative, the discourse exactly replicates the chronology of the substrate. This replication would be one element in what I have termed the accessible rhetoric characteristic of folkloric expressivity. ${ }^{20}$ The narrative genres of folklore tend toward iconic transparency in which the chronology of the experiential substrate and that of the narrative discourse are identical.

The literary narrator, removed from the perishable medium of oral communication, can indulge in the masking of iconicity to a degree inconceivable in oral narrative. Joseph Conrad, to cite one prominent example, tampers with narrative iconicity to such an extent that the reader must invest a great deal of effort in the reconstruction of the probable chronology of the experiential substrate. But even here the iconicity of narrative is recoverable from the discourse. The reader learns to attend to subtle clues, perhaps nothing more thar a marked speaking style, in order to locate a free-floating segment of the narrative discourse in its appropriate spot within the chronology of the substrate. ${ }^{21}$ But when the game between writer and reader gets out of hand and the quest for iconicity becomes ultimately futile (as in some modernist literature), according to the present formulation, we are no longer dealing with narrative but with another expressive form we might label "pseudo-narrative." 22 I am proposing that the iconicity between discourse and its apparent experiential substrate is the defining characteristic of narrative.

\section{Kamsá Mythic Narrative}

While living among the Kamsá Indians of Andean Colombia during the period 1978-79, I witnessed a number of performances of mythic narrative which the Kamsá refer to as antioj palabra, or 'ancient 
words'. ${ }^{23}$ Narratives from this traditional corpus are frequently performed by adults. The most common setting is around the hearth after supper in the evening, though performances of mythic narrative are not restricted to this setting. Every adult Kamsá (and children, too, for that matter) is familiar with portions of this narrative corpus; certain individuals, especially elders, are renowned for their knowledge of the stories and their ability to deliver engaging performances of them.

The labeling of these materials is problematic, yet critical to our present concerns. Stith Thompson observed some time ago, with respect to North American Indian narrative, that "attempts at the exact definition of 'myth' as distinguished from 'tale' seem futile." ${ }^{24} \mathrm{He}$ classified as mythical those narratives "involving an earlier world and primarily devoted to explaining present conditions." 25 In this system, a great deal of narrative material showing close affinities with this mythical corpus (for example, trickster tales, hero tales, and tales of journeys to the other world) falls into a separate category, that of folktale.

Barre Toelken, noting that "many native American tribes see religious experience as something that surrounds man all the time," disputes the classification of Navajo coyote tales as secular narrative. ${ }^{26}$ The Kamsá narrative materials also resist segregation into discrete categories such as myth and folktale. The Kamsá make certain distinctions within their overall narrative corpus, for example, between bngabe palabra, 'our words', and xkenungabe palabra, 'white-people's words', but they recognize antioj palabra as an integral category which comprehends the entire range of traditional narrative associated with themselves and their ancestors.

I propose to refer to the narrative corpus at hand as a vestigial mythology. The religious and ritual connections have largely vanished as Catholic missionaries have imposed upon the Kamsá the religion of the conquistadores. ${ }^{27}$ The narratives are performed today in casual settings appropriate for the narration of a general folktale corpus. Yet elements of the old belief system linger on, and the corpus retains a significant place in the contemporary worldview of the Kamsá. The Kamsá continue to identify the primary model for all correct behavior in these stories and to find confirmation of apparently counterfactual episodes in the topography, flora, and fauna of the empirical world. ${ }^{27}$

In short, the Kamsá community still encounters in this narrative corpus an exemplary experiential substrate centering on events located within the experience of the first ancestors of the present-day people. The central figure in this substrate is bngabe taitá 'Our Father', a syncretic figure comprehending the Catholic Christ as well as the 
culture hero Wangetsmuna. The exemplary character of the actions of the ancestors is conveyed in the oft-heard formula in Kamsá ritual language: ${ }^{29}$

cha-be mundo ts-j-i-ye-ts-a-shekwastona

his world I am following in steps

'In his world I am following in their footsteps'. (i.e., the footsteps of the ancestors)

The discourse formulating and reformulating this seminal experiential substrate preserves intact the iconicity between experience and discourse in the manner typical of a great deal of oral narrative. Some of the narratives are essentially iconic replications and little more, and these can be thought of as a native form of synopsis. ${ }^{30}$ But more often, the narrators sought to breathe life into their verbal icons by dramatizing the events attributed to the mythological experiential substrate.

The methods used by Kamsá narrators to dramatize their performances fall into two sets. One set of devices sustains the iconic relationship between experience and discourse. I have previously used the term metanarration to refer to this class of narrative devices. ${ }^{31}$ Kamsá narrators embellish their stories with periodic manifestations of an editorial attitude towards the events they are describing and thereby foreground themselves as interpreters of an experiential substrate within a performance context. Various elements in the Kamsá grammatical apparatus can be adapted to this purpose, including a set of attitudinal suffixes optionally attached to the nouns. The suffixes are:

-tema: a diminutive, which like the Spanish -ito, implies that the marked object is dear to the speaker.

-jema: a sympathy marker, translatable into English as "poor."

-yema: used to mark an object that is fearfully large or ugly.

Kamsá myths are peppered with these attitudinal suffixes, and they constantly orient listeners to the proper evaluation of the events being related. They belong to what William Labov terms the evaluative apparatus of narrative.

Devices of this kind animate the corpus by encouraging listeners to become emotionally involved in the story. These devices reinforce the iconicity by underlining the presence of a speaking voice, the agency charged with bridging the ontological gap between experiential 
substrate and discourse. They throw into clear relief the iconic structure of narrative, captured in the following diagram:

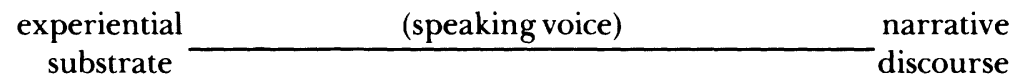

\section{Beyond Iconicity}

The other semiotic mode operating in the myths is that of ostension, whereby a "given object or event . . . is 'picked up' by someone and shown as the expression of the class of which it is a member." ${ }^{2}$ Ostension dispenses with the conventional associative network between a sign and its referent by producing in the flesh, as it were, the item to which reference is to be made. In the case of narrative, the iconic relationship between experience and discourse is momentarily suspended in favor of direct presentation of some portion of the experiential substrate. ${ }^{33}$

The ostension achievable within the limitations of narrative discourse is a virtual ostension; the experiential substrate, existing apart from the discourse, remains in principle remote and untouchable. Ostension produces, as if actually present, a slice of detail belonging to the experiential substrate. If artfully done, it may nourish in listeners or readers the illusion of presencing the actual experiential substrate.

Narratives, then, are constrained to produce the illusion of ostension, which they achieve through a number of rhetorical devices. One type of device, abundantly present in Kamsá myths, involves the covert suggestion, rather than the overt claim, of ostension. These devices of inferential ostension enlist the active contribution of the audience in sorting out the referents of unattached discourse fragments. Kamsá myths contain exclamative interjections which the narrator does not attribute to any protagonist and, therefore, which require the active intervention of the listener's imagination. These expressions include the ubiquitous aray, from the Spanish caray, a euphemistic form of carajo, roughly translatable as 'damnation'; ndelawarda, a Kamsá phrase based on the Spanish y Dios le guarde, 'and God preserve you'; and taiteko, a Kamsá exclamation based on the word for father, 'Taitá, a general term of reverence. These exclamations crop up at key moments, for example, at the arrival of the sun to his earthly abode, which instantly causes a large body of water to dry up, or at the arrival of the dreaded master of the river to the lagoon where the solitary hunter is stranded. ${ }^{34}$ Since these anomalous exclamations are not overtly marked as quotations, the listener must attribute them 
to their most likely source. Because their emotive content is frequently out of keeping with the moderate and objective countenance of the narrator, listeners tend to interpret the exclamations as an echo of the protagonist's thinking or self-address as he confronts his dilemma. The iconicity is shattered; the gap between icon and event is bridged as we find ourselves face-to-face with the distraught protagonists.

Another device of inferential ostension is the gesture of hand, arm, and head used by Kamsá narrators to indicate such things as the relative shape, size, and position of objects mentioned in the discourse. For example, we are shown that the dogs of the volcano are so (insert hand gesture) high, that the perch of squirrel as he tormented bear was about so (insert arm gesture) far above the narrator, and that the hawk-man flew to a limb so (insert head gesture) far above us after metamorphizing into his animal form. ${ }^{35}$ The tacit effect of these gestures is to transform the performance setting into the narrative setting, that is, into the setting attributed to the experiential substrate. Gestures of this sort promote the narrator as the measure of distances, shapes, and sizes lodged in the experiential substrate and, thereby, foster a provisional collapsing of the narrative and performance frames.

Inferential ostension, then, insinuates rather than proclaims the momentary transcendence of iconicity. It requires the active collaboration of the listener, who must creatively align these unattached verbal and kinesic expressions with their appropriate sources. The abundance and distribution of these expressions in Kamsá mythic narrative indicates that they are significant rhetorical devices. Paradoxically, their tentative status as mechanisms of ostension may actually enhance their rhetorical power; by avoiding any direct claim, these devices occasionally penetrate the aura of skeptical conventionality attaching to the more overt forms of narrative ostension.

The most conspicuous move towards ostension Kamsá mythic narrative occurs in the context of direct quotation, a second category which I will refer to as marked ostension. Discourse conventions allow the narrator to claim that the words spoken within the quotation are the words actually spoken by the protagonist at that moment in the experiential substrate. ${ }^{36}$ Segments of reported speech or self-address transcend iconicity by presenting a facsimile of a portion of the experiential substrate. This overlapping of the discourse and substrate frames is possible in these instances only because the spoken word is simultaneously the medium of the event lodged in the experiential substrate and the medium of the narrative discourse. 
The illusion of ostension can be heightened through the skillful use of socially-marked speaking styles. ${ }^{37}$ One manifestation of this potential for illusion is the imitation of animal voices. Kamsá narrators invest considerable energy and skill in the imitation of the voices associated with the animals and animal-people appearing in the narratives. The scurrilous squirrel chuckles to himself after repeatedly fooling the dim-witted bear: chuj, chuj, chuj, chuj; the hawk pecks at the snails which are his favorite foods: pex, pex, pex. The distant voices of the volcanic dogs are imitated in echo form: kwe, kwe; kwe, kwe; kwe, kwe (the second entry of each pair at the interval of a major third below the first entry). ${ }^{38}$

Kamsá narrators often go to great lengths to capture the manner of speaking appropriate to the protagonist. The best narrators carefully imitate the characteristics of the speech variety indicated by the setting and purposes of the reported speech act. In this respect, Kamsá mythic narrative provides a native sociolinguistic commentary, profiling the conventional associations between discourse context and discourse form. The Kamsá speech repertoire provides three distinguishable speech varieties or subvarieties for the purposes of interpersonal dialogue: the ritual language in its saturate form; the ritual language in its attenuated form; and casual conversational Kamsá. Elsewhere I have defined Kamsá ritual language as "a prayerful oratory with distinctive linguistic and performance features, composed during performance on the basis of traditional formulaic and thematic patterns, employed obligatorily in formal ceremonial occasions, and optionally in informal gatherings to honor and persuade."39

Let us examine first the incorporation of Kamsá ritual language in its saturate form into Kamsá mythic narrative. Consider "The Weasel's Story": ${ }^{40}$

\section{The Weasel's Story (plot summary)}

In the old days weasel was a doctor. Deer came down with something so he went to the weasel and solicited her help. Weasel consented, and told deer to remove his clothes and to take a seat in the center of the room. He did so, and she took up her curing branches and began to dance around him, singing "Salt, salt, onion, onion, hot pepper, hot pepper." Deer became suspicious, put his clothes back on, and took his leave, even though weasel assured him that she was doing the cure properly.

Deer returned home and told his father how weasel had made a fool of him. The father listened and then advised his son never to return to 
weasel's house, since deer are food for the weasel and she had been preparing to eat him.

Ritual language appears in this narrative at the moment that deer entreats weasel to cure him:

bata mama t-kmo-j-o-ftse-lesentsia shnana-tem kwa-bwatemaaunt mother to you it was given the cure surely to $\mathrm{ka}$

know

Aunt Mother, God has surely given you the knowledge of the cures.

The selection of the figurative kinship term as the term of personal address, the reference to the divinity, and other grammatical and lexical features mark this speech segment as ritual language. ${ }^{41}$

In "The Weasel's Story," deer solicits the services of weasel in much the way any ailing member of the community addresses the doctor in order to secure his or her services. The precise deployment of his marked speech register enhances the perception of ostension. The narrator signals that this segment of the narrative is to be taken as a presentation of the actual words spoken by deer to weasel through the use of verba dicendi and the reportative morpheme $-k a$. This segment of speech, common to the experiential substrate and the narrative discourse, is formulated in the speech variety appropriate to encounters of this kind. The humor inherent in this situation is enhanced as it becomes apparent that deer has ceremoniously handed himself over to one of his predators. Note that this enhancement is lost in the plot summary which omits (in the manner general to synopsis) the details of the exchange between deer and weasel.

In its attentuated forms, Kamsá ritual language can be described as a flash of formality lodged in a casual discourse environment. Frequently, these flashes of formality take the form of a few vocabulary items associated with the ritual language or of the use of figurative kinship terms as terms of personal address. This transitional sub-variety occurs in a number of mythic narratives, including "The Rabbit's Story," a Kamsá variant of the widely-distributed Tar Baby Tale. ${ }^{42}$

The Rabbit's Tale (plot summary)

In the old days rabbit was a boy in a household charged with scattering scraps of food among the bean plants. He would carry out the basket of scraps, roll about in the dirt, and turn into a rabbit. In this form he would 
feast on the beans. Before returning to the house, he would roll about in the dirt again and assume his human form.

The owners placed a doll made of a honey-derived substance in the path to the garden, hoping to catch the unknown culprit. Rabbit found this doll in his way one day and told it to clear out. When the doll made no move to do so, rabbit punched, kicked, and butted it until he was quite stuck to it. The owners found him there and went to prepare a fire to roast him.

At this point bear came wandering by and inquired of rabbit what he was doing there. Rabbit answered that he was awaiting a fine meal and offered to let bear take his place. Bear agreed, and let rabbit loose. The owners returned to find bear in rabbit's place; they scorched him, and let him go.

A hint of ritual language enters this narrative as rabbit entreats bear to take his place, addressing him as taitá bakó, 'Father Uncle', a respect form used by younger speakers when addressing their elders. Here ritual language bolsters an act of deception.

Narrative incidents of this kind alert us to the fact that ritual language, ostensively a medium of politeness and respect, can be employed in the pursuit of personal goals possibly deleterious to those to whom it is directed. Once again, this moment of ostension captures the original tonalities of Kamsá social intercourse and does so in a manner that is quite likely instructive to even the Kamsá, who normally attend to the positive dimensions of their ritual language.

The absence of ritual language in a segment of reported speech can be equally telling. Consider the following excerpt from "Wangetsmuna," one of the primary mythic narratives of the Kamsá people: ${ }^{43}$

\section{Wangetsmuna (excerpt, plot summary)}

In the old days there was a miner and his younger brother. The miner went off to look for gold while the younger brother stayed behind and cooked. The miner came across a path and wondered what could be passing by there. He set a trap and dreamt that night of a bright-colored bird caught in the trap. When he went the next day to see what he had caught he found a red feather in the trap. He reset the trap, and dreamt that night of a woman caught in the trap. The next day he found her standing there, his rope around her ankle. They conversed and he agreed to follow her home. She turned out to be the sun's daughter. 
The dialogue reported between these two seminal figures in Kamsá mythology is as follows:

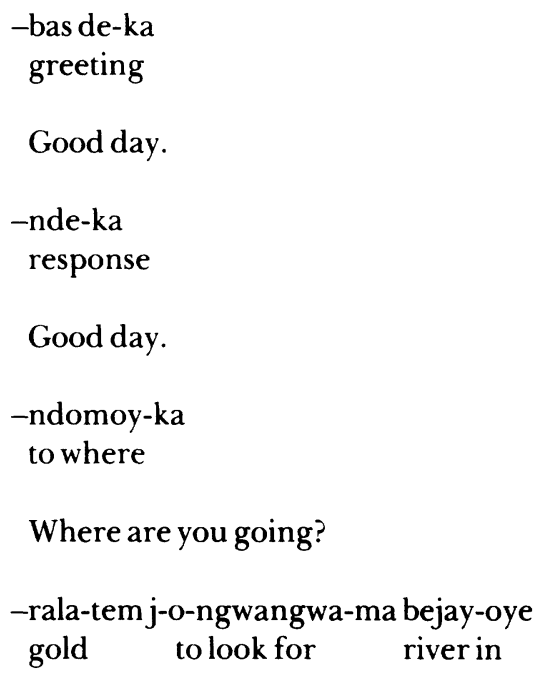

To look for gold by the river.

-chka-ka ndaya-ma mntxá biaja-ka x-k-jenaka waban-iñe so why thus miner you tie me path in

$\mathrm{x}$-mu-tse-jabjona

untie me

Is that so? Why thus, miner, have you tied me in this path? Untie me!

(He unties her; she continues:)

-ke-k-at-j-anemwa atxe-bi-oy j-a-na-ka would you like my place to go

Would you like to go to my place?

-aiñe-ka kwaya-ka yes let's go

Yes, let's go.

This exchange of words initiates a remarkable partnership replete with cosmological meaning for the Kamsá. This meeting between the 
daughter of the sun and the primordial miner precipitates the arrival of Wangetsmuna, who sets about establishing boundaries between the human and animal orders and determining proper modes of diet and sexual exchange.

The variety of Kamsá employed in this exchange is that of everyday, casual speech. The conventions associated with Kamsá ritual language are notably absent here. Although this episode contains a greeting and more than one entreaty, speech acts which lend themselves to elaboration through the ritual language, the speakers remain firmly planted in the everyday variety of Kamsá. Significantly, the sun's daughter addresses the miner as biajá, 'miner', avoiding the polite taitá which is obligatory in the ritual language variety. Even though they have just met, these two converse much as one would expect husband and wife to converse.

The absence of ritual language in this conversational scenario carries an important semantic burden. In the first place, it provides confirmation of the unstated fact that these two personages are to enter into the relationship of husband and wife. Moreover, at the moment of their encounter, Kamsá society still awaits founding, but the ritual language is deeply associated with the Kamsá mythological social order. The absence of ritual language here indicates a dialogue between intimates at an early moment in mythical time, prior to the establishment of the mythological social order. ${ }^{44}$

Kamsá narrators carefully allocate these three ways of speaking to the segments of reported speech within their narratives. To the extent that this usage reflects conversational etiquette outside the narrative frame, the illusion of ostension, of direct confrontation with the experiential substrate, is palpably enhanced. Yet the deployment of sociallymarked speaking styles in mythic narrative is not restricted to this reflective function. Narrators may also exploit this device to produce implicit commentary on the community speech etiquette and to indirectly reinforce or clarify characterizations central to the progress of the narrative.

\section{Narrative Epiphany}

Kamsá mythic narrative, like a great deal of oral and literary narrative, oscillates between two fundamentally different semiotic modalities, those of iconicity and ostension. Iconicity, the definitive modality of all narrative, projects a common chronological order into two discrete realms, narrative discourse and its experiential substrate. While they share a common chronological principle, in other respects 
these two realms are starkly incompatible. Discourse is a conventional sign system, confined to the schematic representation of experience. Many devices directly or indirectly heighten our awareness of iconicity by calling attention to the fundamental disparity between narrative discourse and experiential substrate and the pivotal role of the narrator as agent in translating from one realm to the other.

At the same time, narratives often strive towards the transcendence of iconicity through the creation of the illusion of ostension, the direct presentation of experience. Kamsá mythic narrative displays both inferential and marked forms of ostension, enhancing the illusion of the unification of discourse and experiential frames. These devices momentarily suspend awareness of the inviolable separateness of these two realms: the performance setting becomes, provisionally, the narrative setting; the words of the narrator become those of the narrative protagonist.

These transcendental moments bring about what I refer to as narrative epiphany, the provisional unification of the frames of narrative discourse and experiential substrate. The epiphany I am speaking of shows affinity with the religious notion of epiphany, a breakthrough from the divine plane to the human, as well as with James Joyce's notion of epiphany as the whimsical revelation of the true nature of a thing. ${ }^{45}$ Narrative epiphany has the potential to precipitate a "sudden spiritual manifestation," a moment of radiance in which the essential point of the story "leaps to us from the vestment of its appearance." 46 The tendency of instances of inferential ostension to cluster around key incidents in the narrative and the oft-observed fact that the emotional core of so many narratives resides in their episodes of reported speech lend support to my contention that narrative epiphany is a major dimension of storytelling, retaining some affinity with Joycean epiphany. ${ }^{47}$

Narratives exploiting these two modalities of semiosis, iconicity and ostension, enable the listener or reader to approach their experiential substrates from two contrasting perspectives, one remote and the other intimate. Narratives thereby acquire a kind of three-dimensionality similar to that of material objects. Iconicity in narrative locates the audience members unequivocally outside the frame of the experiential substrate, while narrative epiphany places them in the midst of the action, as witnesses to events rather than as witnesses to the description of events. Narrative epiphany threatens to shake the audience members out of their aesthetic complacency by drawing them into the palpitating theater of life. 
Synopsis, tending to reduce these moments of ostension to mere iconic surfaces, can rightfully be characterized as a flattening process. Clearly, synopsis has its uses (note the presentation of plot summaries in this paper). Furthermore, not every synopsis entirely obliterates the ostensive portions of narrative. Many different degrees of editorial severity are possible in the production of a synopsis from a complete transcription. I do not argue for the abandonment of the procedure, but caution against the reliance on synopsized texts as the ultimate empirical ground for narrative exegesis.

Barre Toelken has written, regarding the oral narratives of the Navajo, that "excessive attention to structure and stated content may actually stand in the way of our seeing those subtle moral implications and conceptual patterns which seem to be the Navajo's main reasons for telling the story." ${ }^{48}$ The failure to confront Kamsá narrative corpus in its integral form would, at the very least, obscure our view of the exploitation of socially-marked speaking styles to enhance the illusion of ostension, to convey information critical to the proper interpretation of the narratives, and to comment on speech usage outside the narrative context. Narrative epiphany, the collapsing of the frame of the experiential substrate onto the frame of the narrative performance, constitutes an important rhetorical strategy in Kamsá mythic narrative. In a great many of these performances, it is the pivotal device in the creation of humor and meaning; it is the means by which, to shift to Joyce's usage, "the object achieves its epiphany." 49

The folklorist who approaches no closer to the actual performances of narrative than the synopsis will remain oblivious to the rhetorical contours discussed in the paper. Proceeding in that fashion, the folklorist forfeits any possibility of responding to narrative as an effective communicative vehicle. Moreover, the very quarry under pursuit, the fundamental meaning of narrative traditions, may escape in the process.

\section{NOTES}

1 I dedicate this paper to the memory of taitá Mariano Chicunque, a consummate Kamsá storyteller who graciously shared with me his tales of the old days. The research for this paper was supported by a Fulbright-Hays Faculty Research Abroad Grant. An earlier draft of this paper was read at the annual meeting of the American Folklore Society in San Antonio, Texas, October 1981. I would like to thank that audience for their lively response. 
2 Claude Lévi-Strauss, The Raw and the Cooked (New York: Harper and Row, 1969), p. 12.

3 Claude Lévi-Strauss, Structural Anthropology (Garden City: Anchor Books, 1967), p. 206.

4 Dennis Tedlock, Finding the Center: Narrative Poetry of the Zuni Indians (New York: Dial Press, 1972); see also Dell Hymes, "Discovering Oral Performance and Measured Verse in American Indian Narrative," New Literary History 8 (1977):433-457, and the essays in Traditional American Indian Literatures: Texts and Interpretations, ed. Karl Kroeber (Lincoln: University of Nebraska Press, 1981).

5 Albert Lord, The Singer of Tales (Cambridge: Harvard University Press, 1960); Sandra Stahl, "The Personal Narrative as Folklore," Journal of the Folklore Institute 14 (1977):9-30; Ilhan Basgoz, "The Tale Singer and His Audience," in Folklore: Performance and Communication, ed. Dan Ben-Amos and Kenneth Goldstein (The Hague: Mouton, 1975).

6 Regarding the limits of translation, see Eugene Nida, Toward a Science of Translating (Leiden: E.J. Brill, 1964); Elizabeth Fine, The Folklore Text: A Performance-Centered Approach (Austin: University of Texas Press, in press); and Jarold Ramsey, "The Wife Who Goes Out Like a Man, Comes Back Like a Hero," PMLA 92 (1977):9.

7 Nils Erik Enkvist, "Experiential Iconicism in Text Strategy," Text 1 (1981): 102 .

8 Ibid., p. 104.

9 John H. McDowell, "The Corrido of Greater Mexico as Discourse, Music and Event," in "And Other Neighborly Names": Social Process and Cultural Image in Texas Folklore, ed. Richard Bauman and Roger Abrahams (Austin: University of Texas Press, 1981).

10 William Labov, Language in the Inner City (Philadelphia: University of Pennsylvania Press, 1972), pp. 359-60.

11 Ibid., p. 360.

12 Seymour Chatman, Story and Discourse: Narrative Structure in Fiction and Film (Ithaca: Cornell University Press, 1978), p. 28.

13 Frank Kermode, The Genesis of Secrecy: On the Interpretation of Narrative (Cambridge: Harvard University Press, 1979), p. 45.

14 Ibid., p. 14.

15 McDowell, "The Corrido."

16 Kenneth Burke, The Philosophy of Literary Form: Studies in Symbolic Action (Berkeley: University of California Press, 1973), p. 1.

17 Kermode, The Genesis of Secrecy, p. 118.

18 See Robert Scholes and Robert Kellogg, The Nature of Narrative (London: Oxford University Press, 1966). 
19 See John H. McDowell, "Some Aspects of Verbal Art in Bolivian Quechua," Folklore Annual of the University Folklore Association 6 (1974):68-81.

20 John H. McDowell, Children's Riddling (Bloomington: Indiana University Press, 1979), pp. 15-17.

21 See Robert W. Stallman, The House that James Built (Lansing: Michigan State University Press, 1961), and A. A. Mendilow, Time and the Novel (London: Deventer, 1952).

22 See Linda Ben-Zvi, "Samuel Beckett, Fritz Mauthner, and the Limits of Language," PMLA 95 (1980): 190.

23 The same terminology appears in Chiapas; see Gary Gossen, "Chamula Genres of Verbal Behavior," Journal of American Folklore 84 (1971):145-68; and Brian Stross, "Speaking of Speaking: Tenejapa Tziltal Metalinguistics," in Explorations in the Ethnography of Speaking, ed. Richard Bauman and Joel Sherzer (London: Cambridge University Press, 1974).

24 Stith Thompson, Tales of the North American Indians (Bloomington: Indiana University Press, 1966), p. xvii.

25 Ibid., pp. xvii-xviii.

26 Barre Toelken, "Seeing With a Native Eye: How Many Sheep Will It Hold?" in Seeing With a Native Eye: Essays on Native American Religion, ed. Walter Capps (New York: Harper and Row, 1976), p. 11.

27 Victor Daniel Bonilla, Servants of God or Masters of Men? The Story of a Capuchin Mission in Amazonia (Harmondsworth: Pelican Books, 1972).

28 See Mircea Eliade, Myth and Reality (New York: Harper and Row, 1963).

29 John H. McDowell, "The Semiotic Constitution of Kamsá Ritual Language," Language in Society 12 (1982):23-45.

30 Dell Hymes has dealt with this phenomenon and the tendency of native synopsis to modulate into native performance in "Breakthrough into Performance," in Folklore: Performance and Communication, ed. Dan Ben-Amos and Kenneth Goldstein (The Hague: Mouton, 1975), pp. 11-74.

31 John H. McDowell, "Performance and the Folkloric Text: A Rhetorical Approach to 'The Christ of the Bible'," Folklore Forum 6 (1973):139-48. See also Barbara Babcock, "The Story in the Story: Metanarration in Folk Narrative," in Verbal Art as Performance, Richard Bauman (Rowley, Mass.: Newbury House, 1977), p. 67.

32 Umberto Eco, A Theory of Semiotics (Bloomington: Indiana University Press, 1973), p. 225. 
In a lecture at Indiana University, Dan Ben-Amos referred to devices of this kind in Benin narrative as "temporal shifters." For another treatment of these two modes of semiosis, see Linda Dégh and Andrew Vázsonyi, "La parola 'cane' morde? Dall'axione alla leggenda, dalla leggenda all'azione," in Festa anthropologia e semiotica, ed. Carla Bianco and Maurizio Del Ninno (Firenze: Nuova Guaraldi Editrice, 1979), pp. 58-71.

34 Two mythic narratives in my collection are referred to here: 1)"Wangetsmuna," one of the key Kamsá myths, which I have in several performances; 2)"Buyesh Ndwenobe Parlo," "The Myth of the Master of the River', which I have from Mariano Chicunque, 1978.

35 I have reference to three mythic narratives from my Kamsá collection here: 1)"Shatjoybiama," 'About the Mocoans', concerning the hunting dogs which emerge from volcanic rock, narrated by Mariano Chicunque in 1978; 2) "Iyendonabiama," 'About Squirrel', part of the Kamsá trickster cycle, narrated by Mariano Chicunque in 1978; 3) “Ngavilanbiama," 'About Hawk', narrated by Mariano Chicunque in 1978.

36 Richard Bauman, Verbal Art as Performance (Rowley, Mass.: Newbury House, 1977), p. 10.

37 See Mihail Bakhtin, Problems of Dostoevsky's Poetics, trans. F. W. Rotsel (Ann Arbor: Ardis, 1973).

38 I have reference to three Kamsá mythic narratives here: 1) "Iyendonabiama" (see footnote 35); 2)“Ngavilanbiama” (see footnote 35); and 3)"Shatjoybiama" (see footnote 35 ).

39 McDowell, "The Semiotic Constitution."

40 "Mamaxbe Parlo," narrated by Mariano Chicunque in 1978.

41 See McDowell, "The Semiotic Constitution."

42 "Coñeshbe Parlo," a very popular trickster tale which I have in several performances. Type 175, Tarbaby and the Rabbit.

43 This excerpt is taken from a performance of "Wangetsmuna" by Mariano Chicunque in 1978.

44 See Jarold Ramsey, Coyote Was Going There: Indian Literature of the Oregon Country (Seattle: University of Washington Press, 1977).

45 James Joyce, Stephen Hero (New York: New Directions, 1944).

46 Ibid., p. 213.

47 The term "emotional core" originates with Tristram Coffin, "Mary Hamilton and the Anglo-American Ballad as an Art Form," Journal of American Folklore 70 (1957):208-14.

48 Barre Toelken, "Poetic Retranslation and the 'Pretty Languages' of Yellowman," in Traditional American Indian Literatures: Texts and In- 
terpretations, ed. Karl Kroeber (Lincoln: University of Nebraska Press, 1981), p. 81.

49 Joyce, Stephen Hero, p. 213. 